\title{
The impact of perceptions of organizational politics on employees' voice: a mediated-moderate model
}

\author{
Xiaoxuan $\mathrm{Cao}^{1}$, Mingjian $\mathrm{Zhou}^{2}$ \\ ${ }^{1}$ School of Economics and Management, Harbin Institute of Technology, Shenzhen, Guangdong, 518000, China \\ ${ }^{2}$ School of Economics and Management, Harbin Institute of Technology, Shenzhen, Guangdong, 518000, China
}

\begin{abstract}
Based on conservation of resources theory, the paper proposes a model demonstrating how perceptions of organizational politics and self-monitoring influence employees' emotional exhaustion and behavior of voice. The model argues that emotional exhaustion may be the mediator between perceptions of organizational politics and employees' voice, and self-monitoring may moderate the mediated relationship. In the end, it discuss the implications and the limitations of the model and suggest some directions for further research.
\end{abstract}

\section{Introduction}

Voice defined as the extent members express suggestions, concerns, or information about a team' s task[1]. With the aggravation of environmental uncertainty, it is more and more difficult to avoid organizational decisionmaking mistakes only by relying on the information mastered by managers. Many managers gradually realize that employees' opinions or suggestions on work can continuously optimize and improve the organizational system, reduce organizational risk and improve organizational effectiveness in the process of organizational development. However, employees generally believe that expressing their opinions publicly will affect the harmony of enterprises and challenge the authority of leaders. It may also bring negative impact on their career development. Therefore, out of consideration of personal gains and losses, employees are generally reluctant to point out relevant issues and express their personal opinions[2].

Perceptions of organizational politics refers to the feelings of organizational members on organizational political behavior[3]. Organizational political behavior is usually considered as a kind of self-interest behavior of employees in order to obtain the maximum interests, which will have a certain impact on all aspects of the organization. At the same time, employees' perceptions of organizational politics will also have a certain impact on employees themselves, thus affecting all aspects of the organization. Previous studies have shown that perceptions of organizational politics affects employees' attitudes, emotions and behaviors, such as organizational citizenship behavior[4], job performance[5] and stress[6].

Although some studies have shown that perceptions of organizational politics can affect employees' organizational citizenship behavior, they rarely explore the direct relationship between them. At the same time, it does not directly discuss the relationship between perceptions of organizational politics and employees' voice behavior. Therefore, on the basis of previous studies, the main purpose of this study is to explore the mediating mechanism of perceptions of organizational politics influencing employees' voice behavior, and further explore the boundary conditions affecting this mechanism. Based on conservation of resources theory, the study proposes a model demonstrating how perceptions of organizational politics affects employees' voice through the mediating role of emotional exhaustion and the moderating role of self-monitoring. The proposed model is shown in Figure 1.

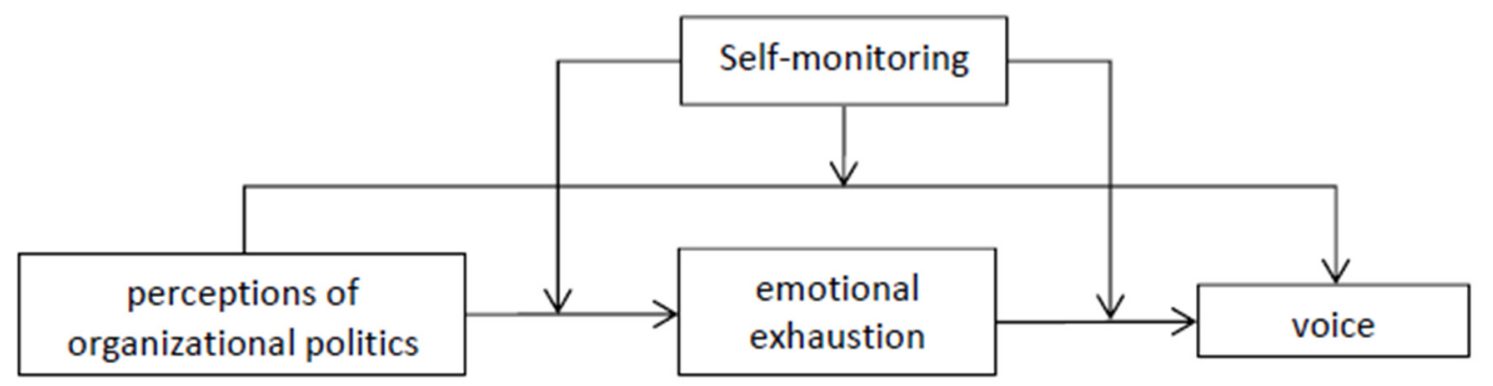

Figure 1. The theoretical model 


\section{Theory and hypothesis}

\subsection{The Relationship between Perceptions of Organizational Politics and Voice}

Previous researchs believe that perceptions of organizational politics reflects a subjective state, that is, the subjective feelings of other employees' organizational political behaviors. On the whole, the research on organizational political behavior has formed three interpretation perspectives: negative, positive and neutral. Scholars with a negative perspective view organizational politics as self-served behavior for personal or collective self-interest, which is destructive. Scholars with a positive perspective view organizational politics as solving organizations conflict, reversing organizational decline and promote personal career success. Scholars with a neutral perspective regard organizational politics as a process of social influence, with the purpose of realizing the rational distribution of scarce resources through power, and the results may be beneficial or harmful.

Most studies conceptualize perceptions of organizational politics as some disgusting factors employees have observed during work. Organizational political behaviors are often considered as pursuing personal goals including striving for in-group status, sucking up to others, backstabbing, rather than the behaviors that are beneficial to the team or organization[7]. Some studies have explored the characteristics of the environment where organizational political behavior exists. For example, in an environment with high organizational political behavior, favoritism, resource allocation and participation in social relationships may be at risk[8].

This paper believes organizational political behavior is that employees make actions beneficial to themselves in order to compete for organizational limited resources. Therefore, when the resources in organization are sufficient and the possibility of redistribution is high, there are high political behavior in organization, which is considered a source of stress[6]. When employees have higher perceptions of organizational politics, their emotional exhaustion is more obvious. Based on conservation of resources theory, when the level of individual perceptions of organizational politics is low, the employees will think the work resources are sufficient. And they may pay more attention to how to obtain more work resources to fininsh the tasks. In this way, they will take actions such as voice. With the increase in perceptions of organizational politics and the consumption of resources, the resources available to employees will gradually decrease, and the employees will reduce their voice behavior. Thus, the paper predicted the following:

Hypothesis 1. Individual perceptions of organizational politics has a negative relationship with voice.

\subsection{Mediated Role of Emotional Exhasution}

Emotional exhaustion is a chronic state of physical and emotional depletion that results from excessive job and/or personal demands and continuous stress. Previous researchs have supported the proposition that perceptions of organizational politics is a source of stress that has adverse effects on employee outcomes, such as job attitudes and performance[3]. Studies have shown that when perceiving high work pressure, individuals will have more self-depletion in response to changing environmental requirements[9]. When individual has more work pressure, he or she will be more emotional exhaustion and more sensitive to resource loss. In contrast, when individual has lower work pressure, he or she is less emotional exhaustion and is more sensitive to resource acquisition.

When perceive organizational political behavior, individuals will feel stress and experience emotional exhaustion due to coping with changing environmental requirements. The negative emotional state of employees easily distracts the attention of employees to achieve task goals, so employees generally consume a lot of resources to adjust their emotions[10][11]. However, the resources that can be used to regulate emotions are limited. If employees continue to gain negative emotional experience at work, they are prone to exhaustion, which will make it difficult for them to comprehensively evaluate the cost of voice, thus affecting their decision on voice behavior[12]. When employees face low organizational political behavior, their emotional exhaustion is low, and they are more likely to have energy to make voice behavior. With the increase of perceptions of organizational politics, their emotional exhaustion degree increases, and they will lose part of energy so that reducing voice behavior. Thus, the paper predicted the following:

Hypothesis 2. Emotional exhaustion has the mediated effects on the relationship between individual perceptions of organizational politics with voice.

\subsection{Moderate Role of Self-monitoring}

Self-monitoring can indicate a person's social effectiveness, interpersonal skills, and the ability to understand which behaviors are appropriate in various situations[13]. It was originally identified as an antecedent to perceptions of organization politics[14]. Subsequently, some studies found that self-monitoring can alleviate the negative impact of organizational political perception on organizational citizenship behavior[15]. High self-monitors are sensitive to cues in the organization and can quickly adjust their attitude and behavior to adapt to the environment. Therefore, when they perceive organizational political behavior, they are more able to see the positive aspects of this behavior, thereby reducing their own resource loss.

For the same organizational political behavior, different employees may have different perceptions toward it. Self-monitoring reflects that individuals can monitor the self presentation, expression and emotional presentation[13]. Low self-monitoring people tend to 
show their true temperament and attitude in various situations, and their cognition and behavior are highly consistent when perceive organizational political behavior and emotional exhaustion. The realtionship between stress and voice via emotional exhaustion is more significant. On the contrary, high self-monitoring people will adjust their behavior[16], and they tend to show high adaptability when they perceive organizational political behavior and emotional exhaustion. They are likely to reduce the impact of perceived organizational political behavior through their own regulation. Therefore, the realtionship between stress and voice via emotional exhaustion is more weaker. Thus, the paper predicted the following:

Hypothesis3. Self-monitoring moderates the mediated effects of individual perceptions of organizational politics on voice via emotional exhaustion in such a way that the mediated effects are weaker in high self-monitoring employees than in low selfmonitoring employees.

\section{Discussion}

\subsection{Implications}

Several implications are associated with the study. Firstly, the model explored the mediating mechanism of perceptions of organizational politics influencing employees'voice behavior and the boundary conditions affecting this mechanism through the mediating role of emotional exhaustion and the moderating role of selfmonitoring, which has realistic meanings to a certain extent. Second, the model has contributions to extend the relevant research on perceptions of organizational politics literature and voice literature. Thus, there is a clear need for research to move beyond bivariate relationships and consider moderators that may explain inconsistent findings in the literature. The model explored the relationship between perceptions of organizational politics and voice, which provides a new direction for future research. Third, this model also brings some meaningful suggestions to managers that employee' s perceptions of organizational politics may decrease the behavior of voice. However, this impact is weaker for employees with high self-monitoring, which indicates managers could cultivate employees' ability of self-monitoring to reduce the impact.

\subsection{Limitations and Future Directions}

Several limitations are associated with the study. Firstly, different types of perceptions of organizational politics may lead to different degrees of emotional exhaustion and thus have different degree of voice. Therefore, future research is encouraged to explore the impact of different types of perceptions of organizational politics on voice behavior, such as perceptions of general political behavior and perceptions of go along to get ahead[17]. Second, perceptions of organizational politics may have different effects on different types of voice behavior. So future research is encouraged to distinguish different voice behaviors, like promotive voice and prohibitive voice[18]. In addition, the paper just put forward a theoretical model which lack of data support. In future, it needs applying practical research to test and verify its correctness.

\section{Conclusion}

Based on conservation of resources theory, the study constructed a model to demonstrate how perceptions of organizational politics affects employees' voice. At the same time, it proposed the mediating role of emotional exhaustion and the moderating role of self-monitoring in this model to explore the mediating mechanism of perceptions of organizational politics influencing employees' voice behavior, and further explore the boundary conditions affecting this mechanism.

\section{References}

1. Morrison, E.W. (2011) Employee voice behavior: Integration and directions for future research. Academy of Management Annals, 5: 373-412.

2. Milliken, F.J., Morrison, E.W., Hewlin, P.F. (2003) An exploratory study of employee silence: Issues that employees don't communicate upward and why. Journal of Management Studies, 40: 1453-1476.

3. Ferris G.R., Kacmar K.M. (1992) Perceptions of Organizational Politics. Journal of Management, 18(1): 93-116.

4. Chang C.H., Rosen C.C., Siemieniec G.M., Siemieniec, G.M. Johnson, R.E. (2012) Perceptions of Organizational Politics and Employee Citizenship Behaviors: Conscientiousness and Self-Monitoring as Moderators. Journal of Business and Psychology, 27(4): 395-406.

5. Treadway D.C., Witt L.A., Ferris G.R., Hochwarter, W.Witt, L.A. Goodman, J. (2005) The Role of Age in the Perceptions of Politics-Job Performance Relationship: A Three-Study Constructive Replication. Journal of Applied Psychology, 90(5): 872-881.

6. Chang, C.H. Rosen, C.C. Levy, P.E. (2009) The Relationship between Perceptions of Organizational Politics and Employee Attitudes, Strain, and Behavior: A Meta-Analytic Examination. The Academy of Management Journal, 52(4): 779-801.

7. Hochwarter, W., Kacmar, C., Perrewé, P., Johnson, D. (2003) Perceived organizational support as a mediator of the relationship between politics perceptions and work outcomes. Journal of Vocational Behavior, 63: 438-456.

8. Valle, M., \& Perrewé, P. (2000) Do politics perceptions relate to political behaviors? Tests of an implicit assumption and expanded model. Human Relations, 53: 359-386. 
9. Hagger, M. S., Wood, C., Stiff, C., Chatzisarantis, N.L.D. (2010) Ego depletion and the strength model of selfcontrol: A meta-analysis. Psychological Bulletin, 136(4): 495-525.

10. Clarkson, J.J., Hirt, E.R., Jia, L., Alexander, M.B. (2010) When perception is more than reality: The effects of perceived versus actual resource depletion on selfregulatory behavior. Journal of Personality and Social Psychology, 98(1): 29-46.

11. Hammer, L.B., Johnson, R.C., Crain, T.L., Bodner, T., Kossek, E.E., Davis, K.D., Berkman, L. (2016) Intervention effects on safety compliance and citizenship behaviors: Evidence from the work, family, and health study. Journal of Applied Psychology, 101(2): 190-208.

12. Burris, E.R., Detert, J.R., Chiaburu, D.S. (2008) Quitting before leaving: The mediating effects of psychological attachment and detachment on voice. Journal of Applied Psychology, 93(4): 912922.

13. Day, D.V., Schleicher, D.J., Unckless, A.L., Hiller, N.J. (2002) Self-monitoring personality at work: A meta-analytic investigation of construct validity. Journal of Applied Psychology, 87:390401.

14. Ferris, G.R. Fedor, D.B. Chachere, G.Pondy, L.R. (1989) Myths and Politics in Organizational Contexts. Group \& Organization Studies: 14(1), 83-103.

15. Rosen, C.C., Levy, P.E., Hall, R.J. (2006) Placing perceptionsof politics in the context of the feedback environment, employee attitudes, and job performance. Journal of Applied Psychology, 91: 211-220.

16. Fuller, J.B., Barnett, T., Hester, K., Relyea, C., Frey, L. (2007) An exploratory examination of voice behavior from an impression management perspective. Journal of Managerial Issues, 19(1): 134-151.

17. Kacmar K.M., Carlson D.S. (1997) Further Validation of the Perceptions of Politics Scale(POPS) : A Multiple Sample Investigation, Journal of Management, 23(5): 627-658.

18. Liang, J., Farh, C.I.C., Farh, J.L. (2012) Psychological antecedents of promotive and prohibitive voice: A two-wave examination. Academy of Management Journal, 55: 71-92. 